\title{
Unusual Puncture Marks on Poly Vinyl Tubing
}

\section{Ramakrishnan PN*}

Physics division, Central Forensic Science Laboratory, Directorate of Forensic Science Services, Ministry of Home Affairs, India

*Corresponding author: Ramakrishnan PN, Physics division, Central Forensic Science Laboratory, Directorate of Forensic Science Services, Ministry of Home Affairs, India, Tel: +914027038429; E-mail: pnrkrishna@rediffmail.com

Received date: January 29, 2018; Accepted date: February 5, 2018; Published date: February 12, 2018

Copyright: (c) 2018 Ramakrishnan PN. This is an open-access article distributed under the terms of the Creative Commons Attribution License, which permits unrestricted use, distribution, and reproduction in any medium, provided the original author and source are credited

\begin{abstract}
The case study involves the examination of puncture marks on a polyvinyl (PV) tubing of an industry pipelining wherein sabotage had occurred. The study carried out to individualize the characteristic and sub-class characteristic marks formed by the tool implemented and their unusual features formed are attempted. The paper also brings out differences in the characteristics of puncture marks on PV tubing resulting from the three knives/tools submitted by the investigating officer and the linking of one of the knives to the questioned tool marks on the tubing.
\end{abstract}

Keywords: Knife; Puncture marks; Tool marks identification; Poly vinyl tubing and point of insertion

\section{Introduction}

A case of suspected sabotage in an industrial pipelining made of polyvinyl tubing was received in the laboratory for examination. As a part of the examination three suspected tools i.e., knives, of which one of the knife was supposed to be involved/implemented was forwarded to the laboratory. It was suspected that one of the knives seized by I.O was involved in the said sabotage. The tool mark examination could succeed in giving a consistent report based on the unusual puncture mark and the characteristic marks formed on the PV tubing.

\section{Material and Methodology}

Three suspected knives marked as knife-1 to knife-3 (Figure 1-3) of which one knife is broken i.e., without handle and the other knife is supposed to be a surgical knife of no 24 was utilized for making test cut marks on P.V. tubing. The Figures $1 \mathrm{a}$ and $1 \mathrm{~b}$ shows the relatively thin blade single edge knife with choil.

The Figure 2a shows the relatively thin blade knife with serrated single edge blade whose handle is broken near the choil. The cutting edge is serrated up to the full length of the blade and is clearly visible in the Figures $2 \mathrm{a}$ and Figure $2 \mathrm{~b}$. The Figure $3 \mathrm{a}$ shows a very thin end sharp blade knife commonly used for surgical application with the provision to remove the blade as seen in Figures $3 \mathrm{a}$ and $3 \mathrm{~b}$.

The Figure 4 is the photograph showing the black colour, $1.7 \mathrm{~mm}$ thickness and $12 \mathrm{~mm}$ diameter cylindrical polyvinyl tubing having the suspected puncture marks/damaged.

The Figure 5 shows the black colour, $1.7 \mathrm{~mm}$ thickness and $12 \mathrm{~mm}$ diameter cylindrical polyvinyl tubing cut and sent by the Investigating Officer (I.O) for the purpose of laboratory test cut marks.

Test cut marks were carried out in the laboratory on the supplied PV tubing by the Investigating Officer on request for making the test cut marks in the laboratory by the authors separately at various positions, directions, and orientations.
For the purpose of the tool marks/puncture mark observation the authors used Leica DM Comparison Microscope of the laboratory with flexible incident lighting and the fibre optic guided lights for proper illumination and photography. Throughout the study the total magnification i.e., both eye piece and objective combined was kept at range from $50 \mathrm{X}$ to $100 \mathrm{X}$.

The total number of test cut marks of six each was made by the each author at different point of times during the entire work.

The approximate angle measured at the "Y" junction on the polyvinyl tubing using the image processing software of Leica Comparison Microscope and was found to be about near to 45 degrees for the Marks made by Knife 1, 38-40 degrees for the knife 2 and less than 30 degrees and between 25-30 degrees for the Knife 3.

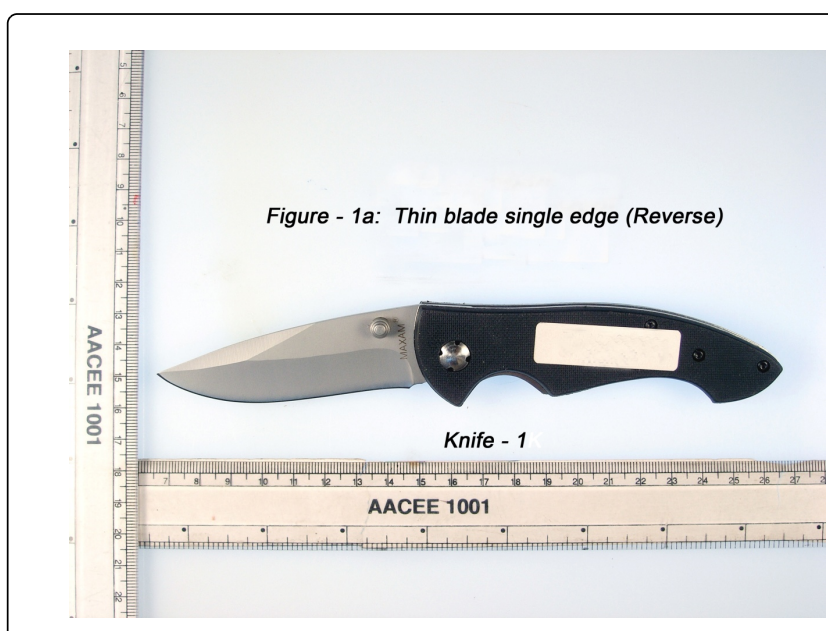

Figure 1a: Thin blade single edge (reverse). 


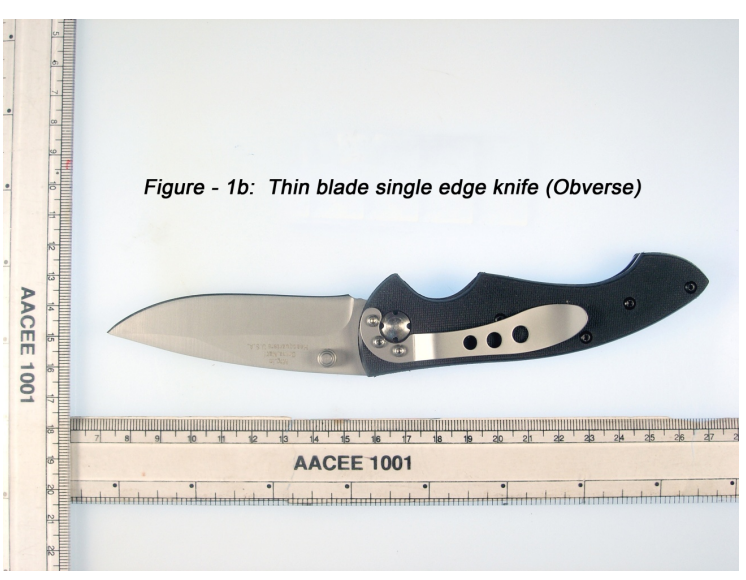

Figure 1b: Thin blade single edge knife (obverse).

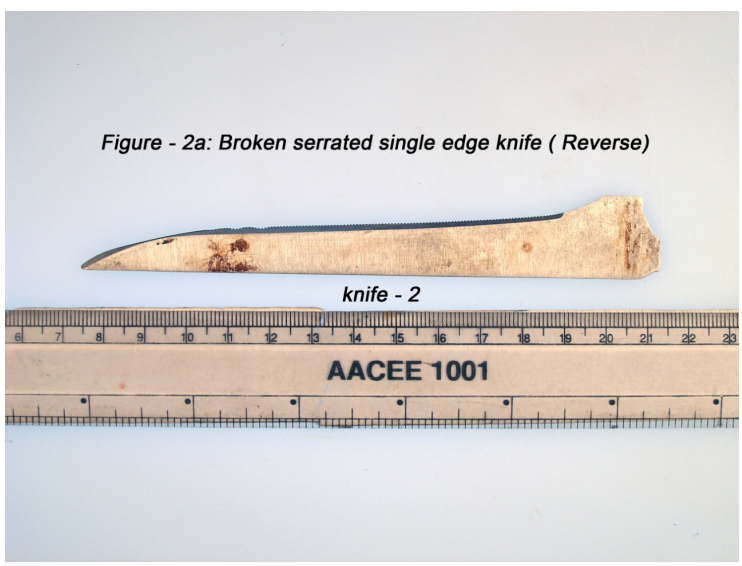

Figure 2a: Broken serrated single edge knife (reverse).

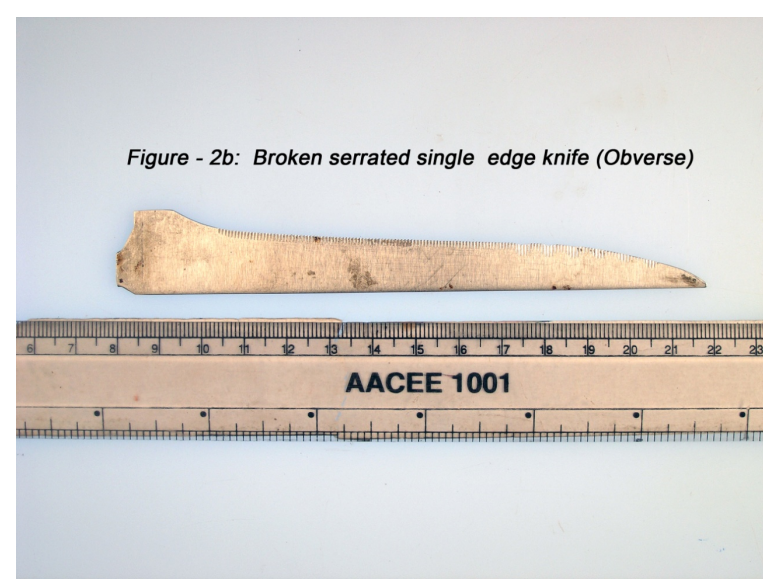

Figure 2b: Broken serrated single edge knife (obverse).

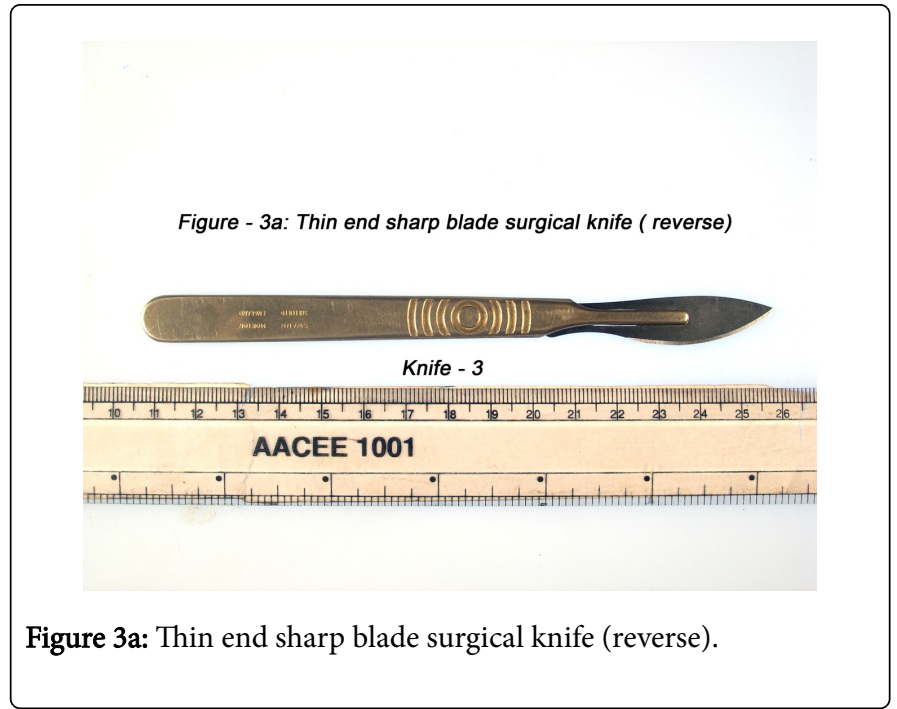

Figure - 3b: Thin end sharp blade surgical knife (Obverse)

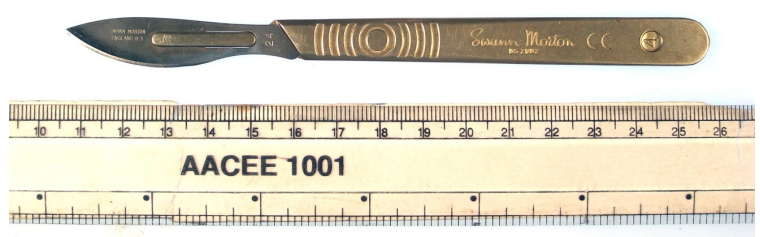

Figure 3b: Thin end sharp blade surgical knife (obverse).

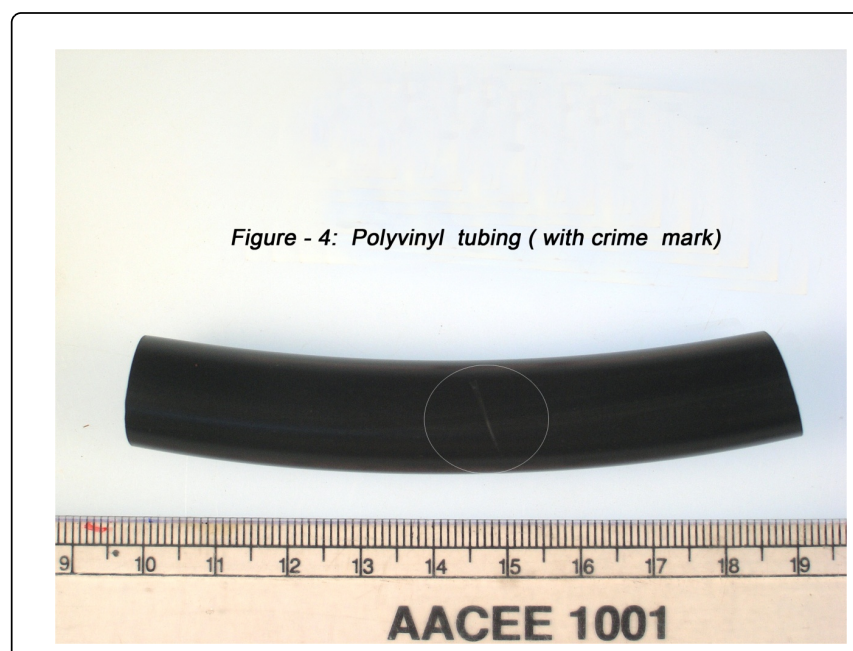

Figure 4: Polyvinyl tubing (with crime mark). 
Page 3 of 4

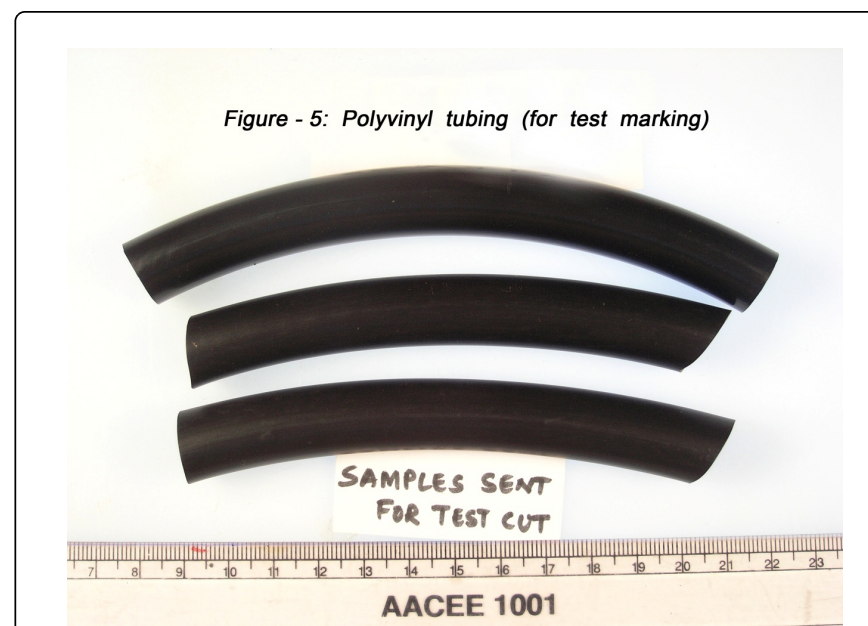

Figure 5: Polyvinyl tubing (for test marking).

\section{Results and Discussion}

The test cut marks made on the P.V. tubing was compared with the suspected cut mark using the Leica comparison microscope. The external view of the puncture made by the knife (Figure 1) depicts several characteristic features as shown in the Figure 6. In this Figure the most obvious characteristic is the friction mark left by the knife blade [1-3].

This friction mark will reflect the general shape and size of the knife's blade portion. This is usually caused by the P.V. material gripping the surface of the knife blade as it enters the tubing. This is the evidence worth looking for in a puncture. It can provide certain clues to link the type of knife used to make the puncture. From the Figure 6 the Point of Insertion (POI) can be identified as the characteristic unusual feature of puncture mark.

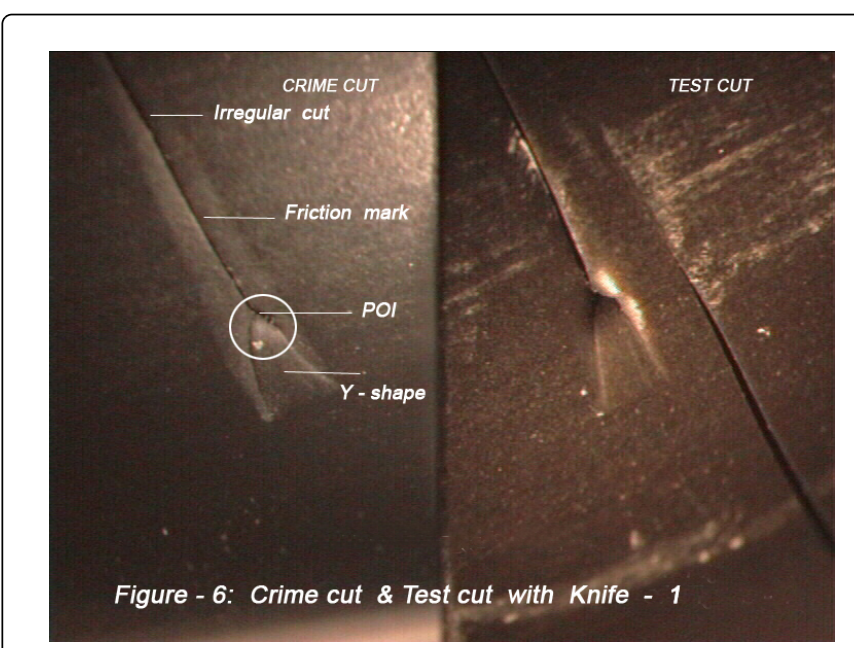

Figure 6: Crime cut and test cut with knife.

The tear mark in POI is the characteristic of a single edge blade knife with blade thickness of approximately 1-3 mm. It has characteristic shape of "snake's tongue or Y". This is caused by the back of the knife tearing the P.V. tube apart as the knife is inserted [1]. This is the point which is having the forensic relevance in determining and forming an opinion that the questioned knife submitted could have made the tube puncture based on the microscopic observation [4] of the punctures.

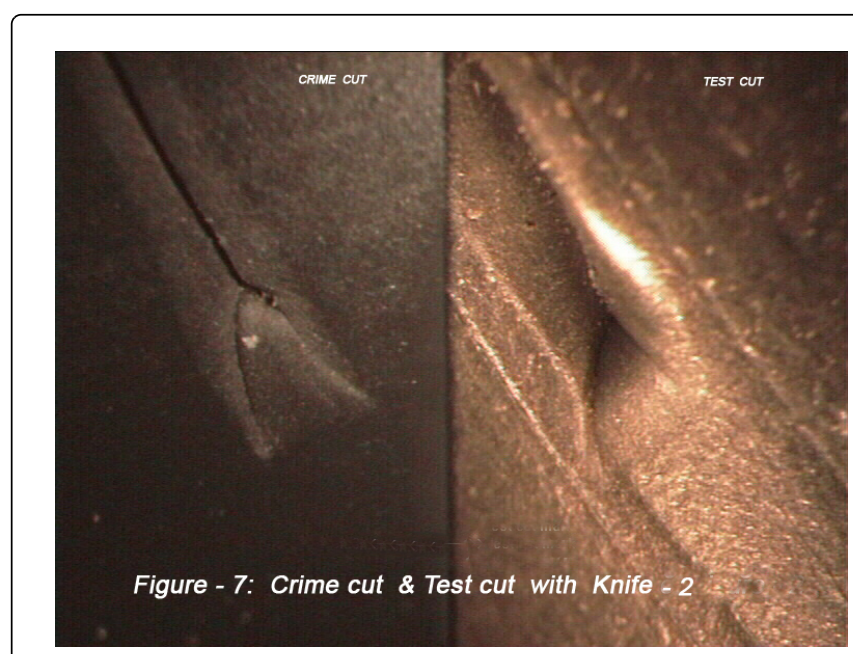

Figure 7: Crime cut and test cut with knife-2.

The Figure 7 shows photomicrography of the puncture marks formed by a relatively thin blade of the broken knife (Figure 2) with serrated single edge blade. The cutting edge is serrated the full length of the blade to the choil. The external view of the cut shown in the Figure 7 gives the friction mark present and POI. Even though this is a single edge blade knife the "snake's tongue- $Y$ " is having a characteristics difference from that of the " $Y$ " in the Figure 6.

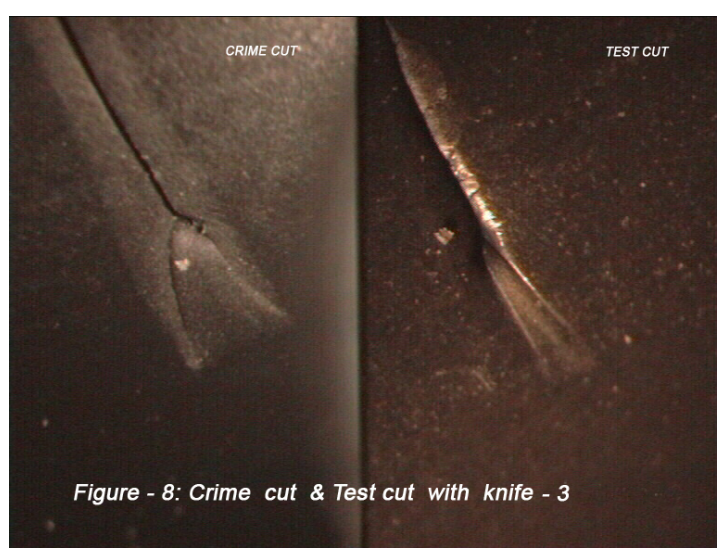

Figure 8: Crime cut and test cut with knife-3.

The Figure 8 shows the comparison microscope observation of the external view of the cut made by very thin sharp surgical knife (Figure 3). The individual characteristics as shown in the Figure 8 have a relatively little detail. The cut is very thin and barely visible. This is because of the small amount of the friction mark present $[5,6]$. The ' $\mathrm{Y}$ ' shape is very irregular and the POI seen is also the exclusive characteristic mark made by the surgical knife. 
Page 4 of 4

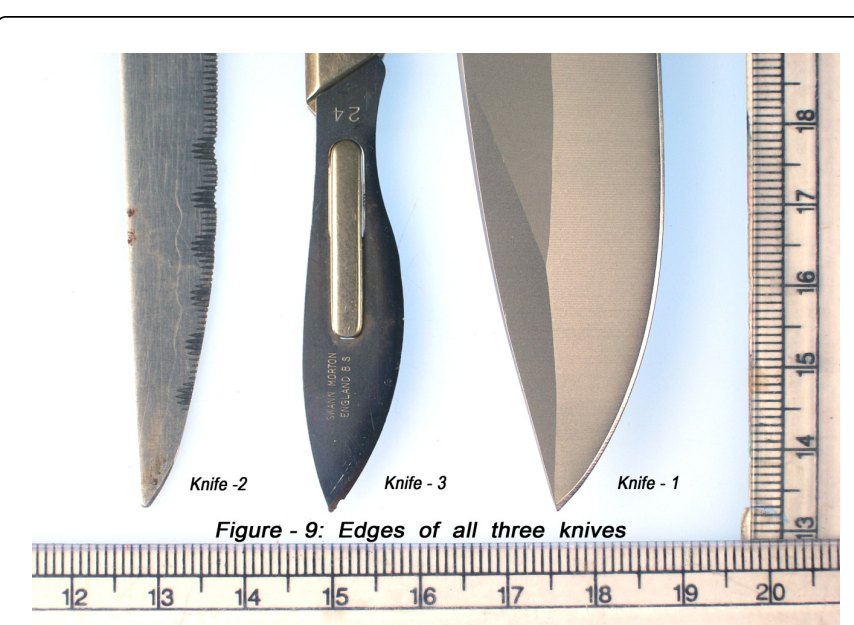

Figure 9: Edges of all three knives.

The comparison made between the puncture marks made by the above said three knives, whose close-up blade edge view is given in Figure 9, on the P.V. tubing showed the difference in puncture made by each knife. The comparison made showed that the knife in the Figure 1 had caused the puncture mark on the tubing shown in the Figure 4 and its comparison shown in the Figure 6.

\section{Conclusion}

A good sharp knife allows puncture with ease and complete control. The puncture marks can be linked as the individual class characteristic mark formed by knife implemented. Friction of the tubing in the form of resistance also plays its role in formation of the characteristic marks.

Forensic tool mark comparison could identify based on the characteristic puncture mark features and link the tool implemented which caused the puncture. Also further study could be conducted for internal tool marks of the tubes formed by puncturing with the knives and the role of the rubber material in the formation of such marks.

\section{References}

1. Ronald LL (2006) Characteristics of knife cuts in tires. AFTE Journal 38 56-63.

2. Love E (1989) Knives and knife terminology. AFTE Journal 21: 490-495.

3. Monahan DL, Harding HW (1990) Damage to clothing-cuts and tears. J Forensic Sci 35: 901-902.

4. Tuira YJ (1982) Tire stabbing with consecutively manufactured knives. AFTE Journal 14: 50-52.

5. Paul LK (1966) Crime investigation-physical evidence and police laboratory. Interscience 118: 256-257.

6. Nichols RG (1997) Firearm and tool mark identification criteria: A review of the literature. J Forensic Sci 42: 466-474. 